\title{
Dos desastres da guerra à violência ao patrimônio histórico: uma análise das obras de Jake e Dinos Chapman \\ Cássia Pérez da Silva ${ }^{1}$ \\ DOI 10.20396/eha.vil4.3380
}

Os irmãos Jake e Dinos Chapman começaram a chamar a atenção da crítica em 1991 com a escultura chamada "Disasters of War", rememorando a obra do artista espanhol Francisco de Goya (1746-1819) com o mesmo título. A obra original de Francisco Coya, Desastres da Guerra, simbolizava a violência presente na guerra, sendo considerada uma das obras mais importantes da representação da Guerra da Independência Espanhola, representando todo o sofrimento e perdas causadas por esta guerra. Francisco de Goya foi o primeiro artista a revelar o lado sombrio da sociedade em situação de guerra e a colocá-lo a público² criando referências para futuras gerações. Os irmãos Chapman, ao criar a sua versão contemporânea, pretendiam criar símbolos de guerras atuais, partindo das noções de violência de Goya para entender as novas formas de violência: mísseis, bombas de todas as classes, armas biológicas e também o terror psicológico provindo da mídia e de todos os veículos de comunicação que ganharam espaço no decorrer dos anos.

Em 2003, os irmãos compraram obras originais da série Desastres da Guerra de Goya e pintaram sobre elas cabeças do personagem da Disney Mickey Mouse, palhaços e burros. Ao fazer este ato, os artistas questionam a ideia de patrimonilização das obras, mostrando que elas podem a qualquer momento ser modificadas pelo atual dono e ainda sim conter valor histórico, renovando -a. Toda a violência presente na guerra continua na tela, porém ao trocar a face das personagens por caricaturas televisivas, a violência se torna uma crítica à sociedade atual e à arte como patrimônio intocável, não deixando-a ser imortalizada pela história com apenas uma visão. Foram taxados de terroristas culturais por destruir obras de tamanha importância histórica.

Analisaremos primeiro a série Desastres da Guerra do artista Francisco Goya para um entendimento mais amplo da obra dos irmãos Chapman, entendendo o artista como precursor estético e conceitual às noções de violências utilizadas pelos artistas contemporâneos. Em seguida, discutire-

\footnotetext{
1 Cássia Pérez da Silva é mestranda no Programa Interunidades Estética e História da arte da Universidade de São Paulo (USP), tendo sua pesquisa financiada pela Coordenação de Aperfeiçoamento de Pessoal de Nível Superior-CAPES.

2 SILVA, 2018.
} 
mos os conceitos de violência apresentados por Slavoj Zikek (2014) propostos a partir de uma análise das obras dos artistas Jake e Dinos Chapman na intenção de aproximá-los às ideias de violência e de patrimônios mutáveis. As noções de violência levantadas pelo autor serão ponderadas quando postas em conjunto aos conceitos de patrimônio em relação às obras dos artistas britânicos.

\section{Desastres da Guerra}

O pintor espanhol Francisco Goya, entre as décadas de 1810 e 1820, criou representações da invasão napoleônica na Espanha em gravuras de água-forte, dando início a uma nova forma de representação em suas obras. A partir dessa série, Goya marca na arte, um novo padrão de receptividade aos sofrimentos ${ }^{3}$.

As perspectivas retratadas por Goya na série de gravuras Desastres da Guerra criam registros de guerra que, até então, não eram retratados de tal maneira: colocam o observador numa posição de segurança, enquanto os sujeitos retratados sofrem e agonizam 4 . O pintor tratava a guerra sem nacionalismos, sem colocar um lado vencedor e outro perdedor; nessa série de gravuras, demonstra que ambos os lados sofrem baixas, provocam a violência e causam/sofrem danos. Durante anos de sua vida, Goya criou rascunhos de desenhos de sofrimento, violência e tortura, alguns posteriormente transferidos para gravuras. O fato de que o pintor não estar presente nessas cenas retratadas, uma vez que já estava em idade avançada e com problemas graves de saúde, nos cria questionamentos acerca dessas reproduções: ao retratar essas cenas como se fossem fragmentos de uma paisagem, colocados junto ao entorno, estaria o pintor facilitando a recepção do observador ao sofrimento, permitindo de ser admirado tal como se admira uma paisagem, ignorando toda a violência ali presente?

Para tanto, nos faz necessário o entendimento acerca do que é violência. Principalmente no contexto de guerras, a violência torna-se elemento fundamental para o funcionamento dos combates, sempre usada de forma a demostrar que existe um lado perdedor e um vencedor. O autor Slavoj Zizek $^{5}$ utiliza-se das noções de Jean-Marie Muller para definir a violência, sendo que

É essencial definirmos a violência de tal modo que nunca possamos qualificá-la como "boa". A partir do momento em que sustentamos a possibilidade de distinção entre uma

\footnotetext{
3 SONTAG, 2003, p.40.

4 SILVA, 2018.

5 Zizek, 2014, p.60.
} 


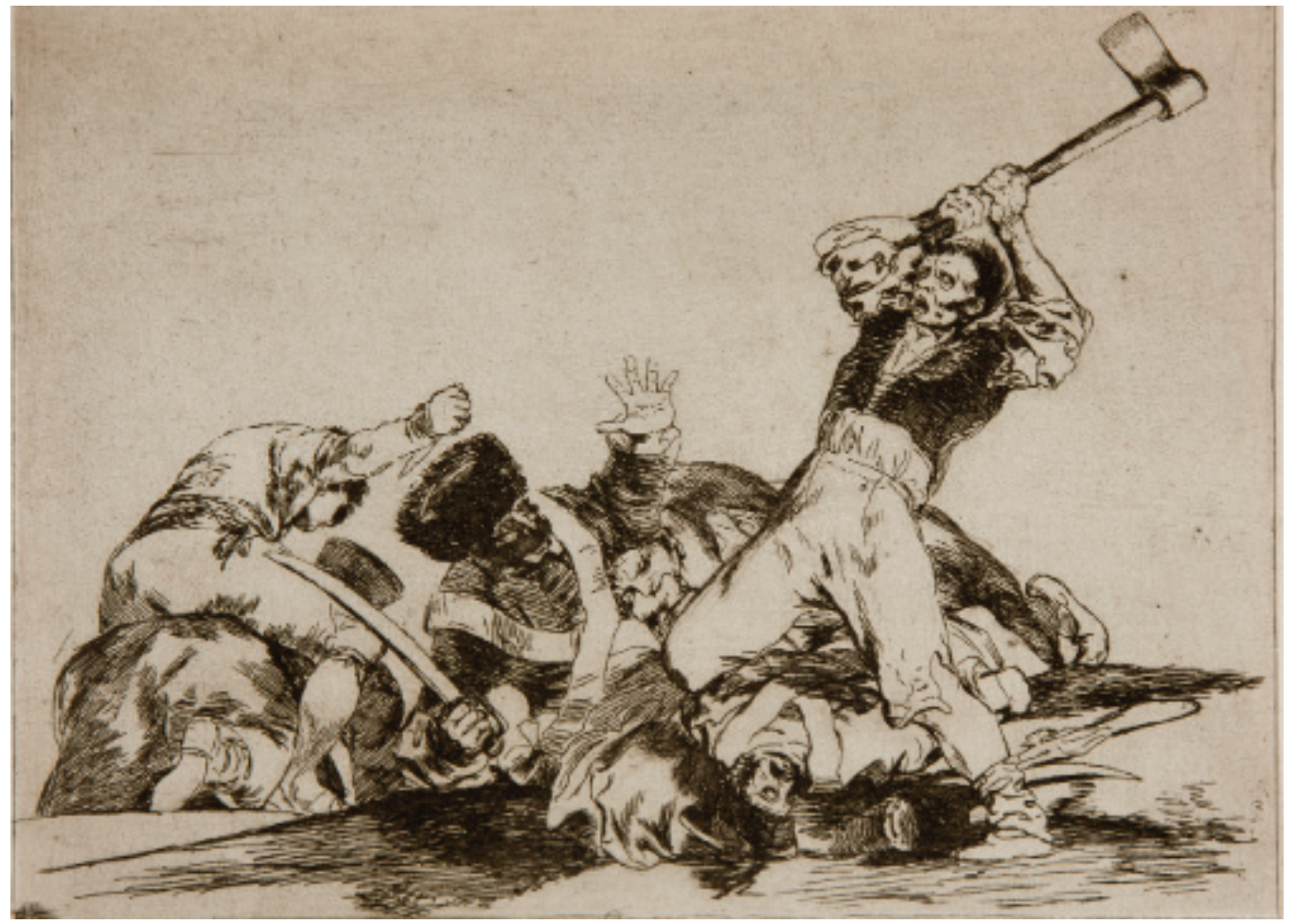

[Figura 1] Francisco Goya, Desastres da Guerra, gravura número 39.

Águaforte sobre papel $17,2 \times 222 \mathrm{~cm}$.

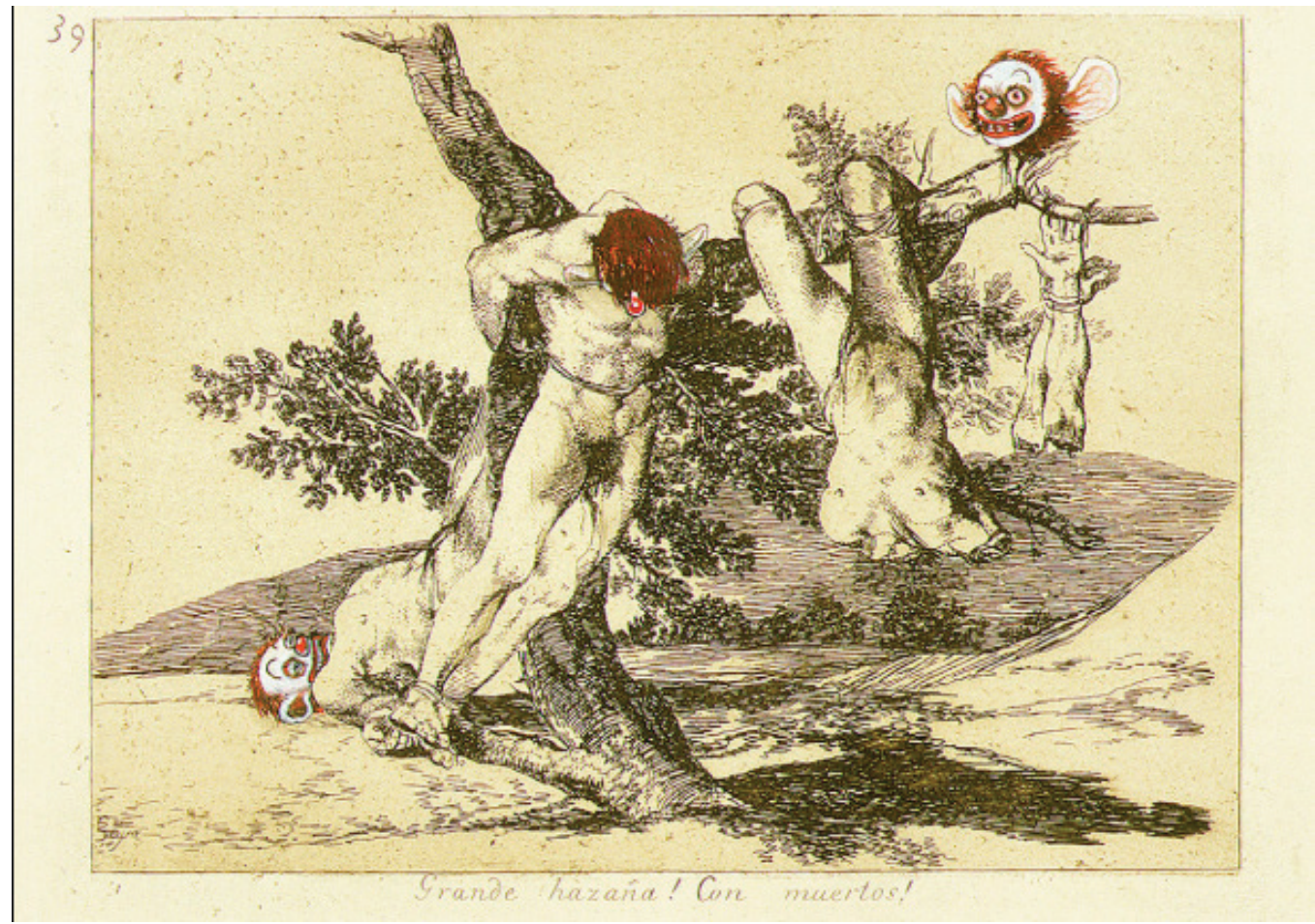

[Figura 2] ]ake \& Dinos Chapman. Creat Deeds — against the dead! Intervenção sobre estampa original.

Águaforte sobre papel, 2003. 17,2 × $222 \mathrm{~cm}$. 
violência "boa" e outra "má", deixamos de poder usar adequadamente a palavra e caímos em um impasse. Acima de tudo, a partir do momento em que passamos a desenvolver critérios que permitam definir uma violência supostamente "boa", cada um de nós poderá facilmente fazer uso dessa noção para justificar os próprios atos de violência. Mas como poderemos rejeitar por completo a violência se a luta e a agressão fazem parte da vida? A solução fácil é uma distinção terminológica entre a "agressão", que corresponde efetivamente a uma "força de vida", e a "violência", que é uma "força de morte": a "violência" aqui não é a agressão enquanto tal, mas o seu excesso que perturba o andamento normal das coisas devido a um desejo que quer sempre cada vez mais. A tarefa consiste em livrarmos desse excesso.

Quando consideramos o contexto de uma guerra, a violência vê-se justificada por ideologias, política e nacionalismos. Essas justificativas criadas para que ocorram guerras, tornam-se, então, justificativas para definir a violência que ali ocorre como "boa", seguindo os parâmetros de Muller uma vez que defende ideais e a nação que está em risco. Zizek (2014), nos ressalta a importância de atentar aos excessos: cada lado pretende defender sua independência perante o outro, mas afirma que "nada é suficiente e nunca ficam satisfeitos; não sabem parar, não conhecem limites; o desejo exige mais, muito mais do que o necessário". ${ }^{7}$

Goya, então, ao nos revelar violências da guerra de maneira cotidiana, nos aproxima dos questionamentos de Zizek (2014): são desastres da guerra tornados obra de arte, para serem observados, apreciados e possuídos, uma violência "boa". A violência que por muitos pode ser vista como atrocidades, tornam-se objetos de desejos a serem guardados e admirado: o desejo exige sempre mais. Apesar de conter no título da palavra Desastres, o que ali retrata torna-se belo para o olhar desapercebido, afastando-se de qualquer tentativa de violência "má".

Retratar o sofrimento do outro, contextualizá-lo e, por fim, torná-lo obra de arte, criam na obra de Goya entendimentos de patrimonialização de suas obras. Suas obras não mais são meras pinturas, mas sim relatos históricos de guerra, de violência, de horror e sofrimento; no entanto, são aclamados com o passar dos séculos e conservados para exibição e contemplação. As obras nos tornam passivos às críticas a violência, nos tornam passivos ao medo e sofrimento que Goya retratou, adicionando novas preocupações referentes à conservação eterna de um patrimônio considerado importante para a cultura. 
2. Patrimônio histórico e a violência

Para o entendimento acerca do patrimônio histórico, utilizaremos as noções de Conçalves (2015). O autor nos dá como um dos critérios para definir um patrimônio histórico a necessidade de criar uma identidade para grupos ou segmentos sociais. O patrimônio não se limita à arte ou arquitetura, atualmente evoluiu para comidas, práticas sociais, qualquer objeto material ou espacial. São, em suma, elementos que criam identidade ao local/grupos que pertencem e que, a partir disso, são necessariamente conservados. Conçalves (2015) aponta que

muitos autores têm recentemente chamado a atenção para a "materialidade" de objetos e espaços, mostrando que estes não funcionam apenas como "suportes", mas também como meios de produção de formas de autoconsciência individual e coletiva ${ }^{8}$. Alguns autores têm assinalado o "poder de agência" dos objetos materiais, chamando a atenção para o fato de que estes são capazes de desencadear efeitos na vida social ${ }^{9}$.

Preservar esses patrimônios torna-se uma necessidade de reafirmação da identidade (individual e coletiva) e de poder estatal, sendo constantemente questionadas as suas funções. Essa reafirmação da identidade torna-se uma faca de dois gumes para o patrimônio: ao mesmo tempo que inclui ações e objetos a serem preservados na memória individual e coletiva de um local/grupo, exclui outros, causando constantemente hostilidade nos patrimônios preservados. A violência ao patrimônio vê-se presente em manifestações de cunho político e ideológico, ressaltando que o patrimônio representa as maiorias, marginalizando as minorias.

As práticas de destruição do patrimônio são indispensáveis para a problematização da memória criada a partir do patrimônio. O processo de patrimonialização ocorre principalmente a partir da exclusão realizada a outros elementos, nos permitindo entender o patrimônio como mutável a partir de noções de épocas. Um exemplo disso podem ser os monumentos à governos ditatoriais presentes na Espanha, que nos últimos anos geraram polêmica ao ser optada pela sua retirada: nesse momento, diferente de quando foram instalados, o atual governo entende que a presença dessas estátuas ocorre como reafirmação de uma época de repressão da ditadura franquista e da guerra civil, sendo uma ofensa estar exposta a público ${ }^{10}$.

O patrimônio como mutável, passivo de alterações e de perder o status de patrimônio varia

\footnotetext{
8 APPADURAI, 2009; KÜCHLER, 2002; MILLER, 2005; TILLEY, KEANE, KÜCHLER, ROWLANDS e SPYER, 2006; WAGNER, 2010; CONÇALVES, GUIMARÃES e BITAR, 2013 in GONÇALVES, 2015.

9 GELL, 1998 in GONÇALVES, 2015.

10 EL AYUNTAMIENTO..., 2016.
} 
de acordo com as noções de cada época, Gonçalves (2015) nos aponta que muitas vezes a destruição e retirada do patrimônio torna-se mais importante que o patrimônio em si. A conservação se vê finita a partir de convenções políticas acerca dos patrimônios.

Neste presente artigo, analisamos a alteração das obras de Goya realizadas por Dinos e Jakes Chapman, sendo as obras de Coya consideradas por muitos autores como patrimônios históricos e fonte de pesquisa. No caso específico de obras de arte, a conservação ocorre de maneira a permitir a contemplação da obra em instituições e coleções privadas. Atualmente, "a tutela não mais se restringe apenas às 'grandes obras de arte', como ocorria no passado, mas se volta também às obras ‘modestas' que com o tempo assumiram significação cultural”11.

Diferentemente de edificações históricas, obras de arte sofrem alterações em pouquíssimos casos. Nas edificações, são realizados alguns critérios para as alterações, que englobam

o respeito pela matéria original; a ideia de reversibilidade e distinguibilidade da intervenção; a importância da documentação e de uma metodologia científica; o uso como um meio de preservar os edifícios e não como a finalidade da intervenção; o interesse por aspectos conservativos e de mínima intervenção; a noção de ruptura entre passado e presente. ${ }^{12}$

As obras de arte, no entanto, dificilmente são passíveis de intervenções uma vez que não possuem necessidade de adaptação do tema para diferentes épocas, mas apenas conservação material. Quando se tornam patrimônio, as obras tornam-se parte da memória e identidade de um grupo/local a partir de um momento histórico que os representem.

\section{Jakes e Dinos Chapman}

Os irmãos Jakes e Dinos Chapman são artistas britânicos que participaram do movimento Young British Artists promovido por Charles Saatchi em 1988. O movimento era composto por artistas formados da universidade Goldsmith na Inglaterra, englobando artistas jovens promissores daquele momento. Desde o começo de sua carreira, os irmãos apresentavam temáticas ligadas à morte, inferno e sofrimento.

No começo dos anos 2000 as obras dos irmãos Chapman passam a ter referências diretas das

11 KÜHL, 2006.

12 Idem. 
obras de Coya: o interesse pelo sofrimento de guerra e tortura, atualizam os temas para a época em que estão e adicionam símbolos presentes na vida cotidiana. Referindo-se a crises econômicas e aos resultados de governos repressivos como o de Margaret Thatcher, suas obras demonstram que o sofrimento perpassa momentos de guerra, atingindo o dia-a-dia das pessoas nas mais diversas formas. Goya, tal como citado acima, nos auxiliou a normatizar o sofrimento, a contemplá-lo como belo; os irmãos Chapman, no entanto, criam representações explícitas e de uma violência exagerada, causando no espectador um desconforto que não cessa.

Zizek (2014), entende que a violência, também, está diretamente ligada à linguagem. É a linguagem que aproxima a violência de "boa" ou "ruim". Os atos de violência sempre estão em conjunto com slogans, frases em cartazes, fotos e imagens que nos remetem a discursos representativos de um grupo específico. No caso das obras dos irmãos Chapman, a violência é explicitada por meio de símbolos que são retratados na mídia e no cotidiano das pessoas, extrapolados até o desconforto.

O desconforto não se limita apenas às suas representações: no ano de 2003 os irmãos fizeram intervenções em 84 gravuras originais de Francisco Goya, iniciando diálogos acerca da destruição de patrimônio e, foram até acusados de terroristas culturais pela mídia. Suas intervenções usavam símbolos como o personagem Mickey Mouse da Disney, palhaços e rostos rindo, um contraponto com a violência retratada pelo pintor espanhol.

Jakes Chapman afirma que seu interesse nos desastres da guerra se encontra no paradoxo do progresso, sendo ele sempre causados de violência ${ }^{13}$. Os irmãos afirmaram que sua atitude de intervenção nas obras originais dá-se a partir de um desejo de criar comoção e chocar os espectadores, tal como Goya fez em seu tempo ${ }^{14}$. O choque criado nos espectadores foi para além dos símbolos usados pelos irmãos na intervenção, o fato de alterarem obras histórias e de criarem uma nova obra a partir da antiga, tensionando noções de patrimônio histórico e autoria.

A partir do momento em que os artistas alteraram as obras de Goya, criaram debates acerca de suas ações. Seriam atos terroristas? Atos de violência? Deveriam ser deixados no original e as intervenções serem feitas em reproduções. Quando consideramos a necessidade de permanência do objeto original, intocado, Silva (2018) entende que

(...) a permanência desses objetos levaria necessariamente à permanência da memória e da identidade, enquanto sua destruição levaria ao esquecimento. Pressupõe-se uma ne-

13 LOS HERMANOS..., 2017.

14 Idem. 
cessária associação entre memória e seus suportes materiais, os quais deveriam ser preservados para que aquela se conservasse. Alguns autores têm recentemente problematizado essa relação, mostrando que não necessariamente a preservação, mas muitas vezes a destruição de objetos e espaços materiais pode ser o elemento gerador de identidades e memórias. A arte da memória transforma-se numa "arte do esquecimento"15.

A alteração feita pelos artistas, então, dá a obra de Coya novas leituras, novos questionamentos, dando abertura para aceitação e negação, mas principalmente para o diálogo acerca da mutabilidade das obras de arte e de sua conservação.

\section{Referências bibliográficas}

EL AYUNTAMIENTO de Barcelona retira la estatua de Franco del Born después que fuera derribada. Disponível em: https://www.eldiario.es/catalunya/barcelona/Derriban-Franco-expuesta-Born-Barcelona_0_571493968.htm Acesso em 22 nov. 2019.

GONÇALVES, José Reginaldo Santos. O mal-estar no patrimônio: Identidade, tempo e destruição. Rio de Janeiro: Estudos Históricos, v. 28, n.55, 2015.

KÜLH, Beatriz Mugayar. História e Ética na Conservação e na Restauração de Monumentos Históricos. São Paulo: Revista CPC, v.1, n.1, p. 16-40, nov. 2005/abr. 2006.

LOS HERMANOS Chapman restauran la "monstruosidad" de los desastres de Goya. Disponível em https://www.elperiodicodearagon.com/noticias/escenarios/hermanos-chapman-restauran-monstruosidad-desastres-goya_1242914. html. Acesso em 22 nov. 2019

SONTAG, Susan. Olhando o Sofrimento dos Outros.Trad. José de Lima. Lisboa: Gótica, 2003.

SILVA, Jason de Lima. Sobre o horror em Coya: caprichos e desastres da guerra. Arte e Filosofia, número 24, 2018.

ZIZEK, Slavoj. Violência, seis reflexões laterais. São Paulo: Boitempo, 2014.

15 FORTY e KÜCHLER, 1999; KÜCHLER, 2002; WEINRICH, 2001 in SILVA, 2018. 